\title{
INDUCED POLYPLOIDY IN PLAICE (PLEURONECTES PLATESSA) AND ITS HYBRID WITH THE FLOUNDER (PLATICHTHYS FLESUS)
}

\author{
C. E. PURDOM \\ Fisheries Laboratory, Lowestoft
}

Received 17.ix.71

\section{INTRODUCTION}

Although polyploidy can be induced readily in a wide variety of plants by chemical and physical agents which affect spindle function, similar studies in animals are rare and restricted mostly to amphibia (Fankhauser, 1945). In fish, triploidy has been induced by the application of temperature shocks to newly fertilised eggs. Svardson (1945) produced a single triploid embryo amongst 161 cold-shocked eggs of a cross between Salmo salar and S. trutta and another amongst 30 eggs of Coregonus laveratus. Neither was reared beyond the blastula stage. Swarup (1959a) produced triploid sticklebacks (Gasterosteus aculeatus) and was able to rear them to their full size. Juvenile triploids were as viable as diploid controls but differed from them with respect to certain body proportions (Swarup, 1959b). However, the growth rate and final size achieved by the triploids were the same as in diploid controls, despite the increased cell size observed in the triploids. This lack of dependence of growth rate on the degree of ploidy was also observed in the work with amphibia (Fankhauser, 1941) but is in contrast to the situation in plants and some invertebrates, where growth rate or final size was often positively related to the degree of ploidy. It was concluded that sizeregulatory mechanisms were responsible for the lack of an effect of polyploidy on growth rate in vertebrates.

Diploid gynogenesis has been reported in a number of fish species including cyprinids, sturgeons, loaches, salmonids and pleuronectids (Romashov et al., 1961 ; Purdom, 1969). The frequence of diploid embryos was greatly increased by the application of a cold shock to eggs after fertilisation. Diploidisation under these conditions was shown to be due to retention of the second polar body (Purdom, 1969), and it therefore seems probable that triploidy could also be induced in eggs of plaice and other species of fish by applying cold shocks, as in the gynogenesis experiments, but after fertilisation with normal spermatozoa.

A further possibility was the induction of tetraploidy by the suppression of nuclear division following the application of the cold shock during the first cleavage mitosis of normally fertilised eggs. In amphibian gynogenesis, diploidisation is reported to be due in part to this type of event (Kawamura, 1939; Subtelny, 1958).

Experiments reported here examine the possibility of producing polyploids in plaice and its hybrid with the flounder, by the use of cold shocks applied between fertilisation and first cleavage. Growth rate, gonad development and the phenotypic characteristics of possible allo-polyploids were also studied, since these are features which might be of relevance in fish 
cultivation. Growth rate was normal in Swarup's triploid sticklebacks but these fish have a determinate growth pattern. Plaice have an indeterminate growth pattern in the sense that they continue to grow throughout life (Wimpenny, 1953), and size-regulatory mechanisms, of the type proposed by Swarup for sticklebacks, would be absent.

\section{Materials AND MEthods}

Ripe plaice (Pleuronectes platessa) and flounders (Platichthys flesus) were collected from the North Sea during the 1969-70 spawning season. Eggs were fertilised artificially and incubated at $8^{\circ} \mathrm{C}$. After hatching, larvae were reared at $10^{\circ} \mathrm{C}$. and fed newly hatched Artemia nauplii through metamorphosis, when the temperature was increased to $15^{\circ} \mathrm{C}$. and the fish maintained on a diet of white worms (Enchytraeids) and ragworm (Nereis spp.).

Cold shocks were applied to newly fertilised eggs by pouring them, with a small quantity of sea water at $8^{\circ} \mathrm{C}$., into a container with sea water at its freezing point of about $-1.7^{\circ} \mathrm{C}$. This produced final temperatures of $0 \cdot 0-0.5^{\circ} \mathrm{C}$. Temperature was held at approximately $0^{\circ} \mathrm{C}$. for 2 to 4 hours, after which the egg containers were returned to the $8^{\circ} \mathrm{C}$. room and allowed to regain this temperature.

To induce triploidy, the cold treatment was started 15 minutes after fertilisation, since this had been found to be the best timing for diploid gynogenesis (Purdom, 1969). Tetraploidy was attempted by applying the cold shock over a range of times from 2 to 5 hours after fertilisation.

Several tests were employed to determine whether or not the treatments were effective in inducing polyploidy. Direct chromosome counts were not attempted, since cytology of these small fish eggs is very difficult and the newly hatched larvae show very little nuclear division. A simple genetic test was available for the detection of triploids, using characteristics of the hybrid cross between plaice and flounder. These hybrids are intermediate between the parents for larval pigmentation and various meristic characters (Pape, 1935;.Von Ubisch, 1953) and it was predicted that the triploid from a cross of plaice female $\times$ flounder male would be intermediate between the hybrid and the plaice, since its genetic constitution would comprise two sets of plaice and one of flounder chromosomes. Larval pigmentation was examined in live larvae 1 week after hatching and meristic characters were obtained from alizarin-stained specimens killed 8 weeks after hatching. A final check on presumed triploids was made by measurement of nuclear size in erythrocytes from metamorphosed fish. Blood smears were stained with Leishmann's stain and microphotographed with an image scale of 680. Measurements were made on prints enlarged five times.

Phenotypic tests were not available for the detection of tetraploidy, but since it was expected to arise from the non-separation of the products of first mitosis it should result in a delay, equivalent to the duration of one cell cycle, in the appearance of 1 st cleavage. Samples of live eggs were therefore examined at short intervals during the period from fertilisation up to the 1 st or 2 nd cleavage stages. Where there was evidence of delay, fish were reared beyond metamorphosis for examination of nuclear size in erythrocytes.

The post-metamorphosis growth rates of plaice, plaice $\times$ flounder hybrids, plaice and hybrid backcrosses, and plaice $\times$ flounder triploids were compared 
by rearing groups of approximately 20 fish of each type under standard conditions and with ad libitum feeding with live foods. The fish were maintained 10 to a tank in 30 litre tanks at a temperature of $15^{\circ} \mathrm{C}$. and with a 30 litre per day flow of water. Length measurements were made in situ every 2 weeks with callipers, thus avoiding undesirable handling of the fish during the experiment.

Most of the work reported here was done with hybrids between plaice females and flounder males. This cross was chosen partly for the genetic reasons already advanced but also because these hybrids are much hardier and easier to rear than plaice.

\section{REsults}

\section{(a) Production of triploids}

Plaice eggs fertilised by flounder sperm were divided into two groups, one of which received cold treatment from 15 minutes after fertilisation for $3 \frac{1}{2}$ hours. A further batch of eggs from the same female was fertilised with

TABLE 1

Melanophore counts on post-anal body and fins in plaice, plaice $\times$ flounder hybrids and presumed triploid larvae

$\begin{array}{clrcc}\text { Group } & & \overbrace{1} & 2 & 3 \\ \text { Plaice } & \text { Body } & 171 & 165 & 160 \\ & \text { Fins } & - & - & - \\ \text { Hybrid } & \text { Body } & 276 & 327 & 295 \\ & \text { Fins } & 158 & 149 & 172 \\ \text { Triploid } & \text { Body } & 163 & 173 & 99 \\ & \text { Fins } & 40 & 15 & -\end{array}$

plaice spermatozoa. Embryological development was normal in all groups except that 1st cleavage was delayed by about 2 hours in the cold-treated eggs. Hatching began in both hybrid groups 12 days after fertilisation and in the plaice 15 days after fertilisation. By 3 weeks after fertilisation, larval pigment patterns were sufficiently developed to distinguish each of the three groups. Plaice larvae showed moderate body pigmentation but a complete absence of melanophores in the marginal fins. Plaice $\times$ flounder hybrids were heavily pigmented on the body and in the fins, whilst the larvae from the hybrid cold-shocked eggs were intermediate between plaice and plaice $x$ flounder hybrids. This could be clearly seen with the naked eye, but table 1 lists melanophore counts from three larvae selected at random from each of the three groups. The intermediacy of the triploid group is obvious, with respect to fin pigmentation. As there is no reason to suspect that such an effect could arise through the cold treatment per se, the evidence strongly suggests that the cold-shocked hybrids were triploid. This was subsequently supported by measurement of nuclear size in erythrocytes of metamorphosed fish (table 2). The mean area of the nuclei in the "triploid" group was significantly larger than in the diploids and the ratio of areas approximates to $1.4: 1$. If the volumes of triploid and diploid nuclei were in the ratio 
$3: 2$, the areas of their elliptical planes would have an expected ratio of $1 \cdot 3: 1$, which is close to the observed value.

The production of triploids in this way was repeated five times with similar results. Several hundred larvae and fish from cold-shocked eggs were examined and all appeared to be triploid.

TABLE 2

Mean areas of erythrocyte nuclei in plaice, plaice $\times$ flounder hybrids and possible polyploids. Area expressed in $\mathrm{sq} . \mathrm{cm}$. at a magnification of $\times 3400$

Mean values from 6 measurements on each fish

\begin{tabular}{|c|c|c|c|c|c|c|c|}
\hline Fish & 1 & 2 & 3 & 4 & 5 & $\begin{array}{c}\text { Overall } \\
\text { mean }\end{array}$ & S.E. \\
\hline Plaice & $1 \cdot 77$ & $1 \cdot 78$ & $1 \cdot 91$ & 1.66 & - & $1 \cdot 78$ & $0 \cdot 14$ \\
\hline Hybrid & $1 \cdot 51$ & 1.67 & $1 \cdot 71$ & 1.66 & $1 \cdot 40$ & $1 \cdot 59$ & 0.14 \\
\hline "Triploid" hybrid & $2 \cdot 52$ & $2 \cdot 74$ & $2 \cdot 32$ & $2 \cdot 19$ & $2 \cdot 30$ & $2 \cdot 41$ & $0 \cdot 14$ \\
\hline "Tetraploid" hybrid & $1 \cdot 88$ & 1.66 & $1 \cdot 70$ & 1.87 & $1 \cdot 68$ & $1 \cdot 76$ & $0 \cdot 14$ \\
\hline
\end{tabular}

\section{(b) Attempted production of tetraploids}

A batch of plaice eggs was divided into six aliquots, one of which was run as a control. The other groups received 2-hour cold treatments, the first starting at 4 hours after fertilisation, the second at 4 hours 15 minutes after fertilisation and so on up to 5 hours after fertilisation. The onset of 1st cleavage was monitored in samples of eggs from each group. In the controls, anaphase was observed at 4 hours 35 minutes after fertilisation and telophase was completed by 4 hours 49 minutes, when the plane of cleavage became apparent; the complete two-cell stage was reached by 5 hours after fertilisation. In those groups given cold treatment from 4 hours 30 minutes after fertilisation, or later, the two-cell stage was completed within 5 minutes of the end of the cold treatment with no cleavage delay other than could be attributed to the low temperature during treatment. The groups coldtreated from 4 hours and 4 hours 15 minutes after fertilisation, however, both showed additional delay in cleavage. In the 4-hour groups nuclear activity started immediately after the cold treatment, but the eggs eventually developed into a one-cell stage at 6 hours 50 minutes after fertilisation. This single-cell stage is never seen in normal eggs. Cleavage began in these eggs at 7 hours after fertilisation and thus showed a delay of about 1 hour relative to the other cold-treated groups. Similar phenomena occurred in about 30 per cent. of the eggs cold-treated from 4 hours 15 minutes after fertilisation; the rest developed normally, with delay consistent with the cold treatment received. There was evidence, therefore, that cold treatments applied at about 4 hours after fertilisation suppressed the first cell division. This experiment was repeated and the results (table 3 ) show that the delay in lst cleavage was only 1 hour 40 minutes for group B cold shocked from 15 minutes after fertilisation, whilst in groups G-E, cold shocked from 3 hours 15 minutes, 3 hours 30 minutes and 3 hours 45 minutes after fertilisation respectively, the delay in lst cleavage ranged from 2 hours 30 minutes to 3 hours 50 minutes. There was evidence, however, that the 2 nd cleavage division was accelerated in these three groups. In groups $\mathrm{C}$ and $\mathrm{D}$, the four-cell stage was only delayed 2 hours, compared with control group A, and in groups $\mathrm{E}$, one or two four-cell stage eggs were observed at the time when most of the eggs first entered the two-cell stage. This latter point was 
demonstrated conclusively in a further experiment in which eggs cold shocked 4 hours after fertilisation developed either directly from the "singlecell " stage to the four-cell stage, or from two to four cells, within 5 minutes. Thus, although 1st cleavage appeared to have been suppressed by cold shocks starting around 4 hours after fertilisation, compensation occurred such that 2 nd cleavage stages appeared to be delayed only by an amount consistent with a physiological effect of the cold treatment. These eggs

TABLE 3

Time of cleavage in plaice eggs subjected to cold shocks (except A) of 2 hours' duration. (All times are in hours and minutes after fertilisation: those in columns 3-6 are to the nearest 5 minutes)

$\begin{array}{cccccc}\text { Group } & \begin{array}{c}\text { Start of } \\ \text { cold shock }\end{array} & \begin{array}{c}\text { Anaphase } \\ \text { stage }\end{array} & \begin{array}{c}\text { 4-cell } \\ \text { stage }\end{array} & \begin{array}{c}\text { Cleavage } \\ \text { delay }\end{array} \\ \text { A } & \text { None } & 4.35 & 5.00 & 6.55 & - \\ \text { B } & 0 \cdot 15 & 6.25 & 6.40 & \text { n.o. } & 1.40 \\ \text { C } & 3.15 & \text { n.o. } & 7 \cdot 30 & 8.55 & 2.30 \\ \text { D } & 3.45 & 8 \cdot 15 & 8.30 & 8.50 & 3.30 \\ \text { E } & 4.06 & \text { n.o. } & 8.50 & \text { n.o. } & 3.50\end{array}$

n.o.-Not observed.

should therefore be diploid and this was confirmed by measurement of nuclear size in erythrocytes from metamorphosed fish (table 2).

The behaviour of the nucleus during the development of the single-cell stage and its subsequent transition into the four-cell stage was examined in eggs fixed in Davidson's fixative (Mahoney, 1966) and stained with haematoxylin. The majority of the single-cell stages contained two nuclei, lying very close together. After the second mitotic division, a cell wall was formed at right angles to the two spindles, and this was followed, either immediately or up to several minutes later, by the appearance of what should have been the cell wall at lst cleavage. Thus, in the majority of eggs cold shocked

TABLE 4

Observed cell numbers in eggs mid-way between the expected four- and eight-cell stages

\begin{tabular}{|c|c|c|c|c|}
\hline & \multicolumn{4}{|c|}{ Number of cells } \\
\hline & 1 & 2 & 3 & 4 \\
\hline Untreated eggs & - & 4 & 1 & 124 \\
\hline Cold-treated eggs & 1 & 14 & 1 & 108 \\
\hline
\end{tabular}

during first mitosis, the separation of daughter nuclei was achieved but no cell wall was laid down between them. This cell wall appeared only after the second mitosis was completed.

Although the majority of eggs developed into four-cell stages some did not. Table 4 lists the frequencies of cell numbers in untreated eggs and in eggs given 2-hour cold treatment from 4 hours after fertilisation. These eggs were fixed at 10 hours 40 minutes and 9 hours 10 minutes after fertilisation, respectively. At these times the embryos should be mid-way between the four- and eight-cell stages. There were two-cell stage eggs in both groups but the frequency was significantly higher in the cold-treated eggs $\left(\chi^{2}=10 \cdot 6\right.$, 1 d.f., $\mathrm{P}<0 \cdot 0016)$. 
(c) Survival of triploid eggs and larvae

The viability of eggs and early larvae of plaice is highly variable, particularly after production by artificial fertilisation. Many factors appear to be involved, including buoyancy, shape and size of the eggs and clarity of the egg membrane. These features of egg quality are difficult to control and cause great differences between batches of eggs. In general, treatment of

TABLE 5

Survival of diploid and triploid eggs at 6,12 and 19 days after fertilisation

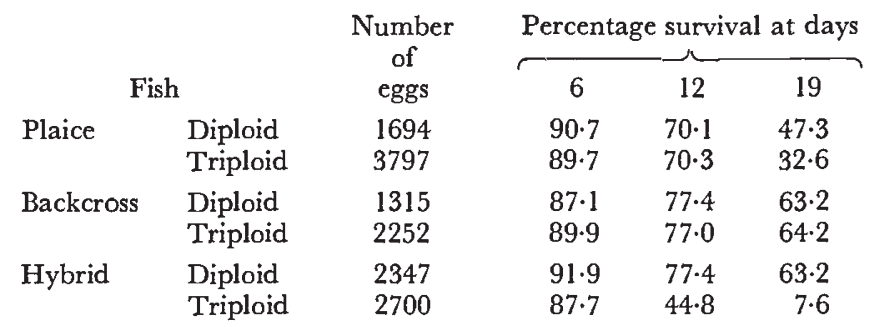

eggs with cold shocks did not appear to influence the survival rates of embryos or early larvae. Routine counts of dead eggs and larvae were not made, but mortalities were monitored up to 19 days after fertilisation in one series of triploid trials, and up to 90 days after fertilisation for samples of the larvae. These trials comprised a comparison of diploids and triploids in plaice, plaice $\times$ flounder hybrids, and plaice $\times$ hybrid backcrosses. The data on egg and early larval survivals are summarised in table 5, and the performance of larvae through metamorphosis in table 6.

TABLE 6

Survival of larvae from first feeding at 20 days after fertilisation, through metamorphosis

\begin{tabular}{|c|c|c|c|c|}
\hline & & Number of & $\begin{array}{r}\text { Percent } \\
\text { at }\end{array}$ & $\underset{\text { survival }}{\text { suris }}$ \\
\hline & & at 20 days & 60 & 90 \\
\hline Plaice & $\begin{array}{l}\text { Diploid } \\
\text { Triploid }\end{array}$ & $\begin{array}{l}179 \\
201\end{array}$ & $\begin{array}{l}66 \cdot 5 \\
69 \cdot 2\end{array}$ & $\begin{array}{l}27 \cdot 9 \\
36 \cdot 5\end{array}$ \\
\hline Backcross & $\begin{array}{l}\text { Diploid } \\
\text { Triploid }\end{array}$ & $\begin{array}{l}180 \\
182\end{array}$ & $\begin{array}{l}57 \cdot 2 \\
57 \cdot 2\end{array}$ & $\begin{array}{l}50 \cdot 0 \\
47 \cdot 8\end{array}$ \\
\hline Hybrid & $\begin{array}{l}\text { Diploid } \\
\text { Triploid }\end{array}$ & $\begin{array}{l}195 \\
175\end{array}$ & $\begin{array}{l}80 \cdot 0 \\
75 \cdot 4\end{array}$ & $\begin{array}{l}78 \cdot 5 \\
74 \cdot 3\end{array}$ \\
\hline
\end{tabular}

Survival percentages were similar in all groups up to 12 days after fertilisation, except for the triploid hybrids; this group of eggs showed a catastrophic death rate for which no explanation could be found. From 12 days after fertilisation, the time at which hatching began, mortalities were heavier for the plaice than for the other groups, excepting the anomalous group of triploid hybrids. At 19 days after fertilisation, the survival of plaice triploids was lower than that of diploids, but for the backcrosses survival was the same for diploids and triploids (table 5). Survival of larvae from first feeding through metamorphosis (table 6) also showed that plaice were 
less viable than hybrids, as is well known, with the backcrosses occupying an intermediate position, as might be expected. Again there was no obvious difference between triploids and diploids within each series. Viability of triploids was also good after metamorphosis and no difficulties have been experienced in maintaining these fish up to 18 months of age at the present time. There was no evidence, therefore, that the induction of triploidy adversely affected viability at any stage in the development of fish from eggs to maturing juveniles.

(d) Meristic and morphological characters

Mean vertebral number and mean length at 8 weeks of age are shown in table 7 for plaice, plaice $\times$ flounder hybrids, plaice $\times$ plaice $/$ flounder back-

TABLE 7

Mean lengths and vertebral numbers at 8 weeks of age

\begin{tabular}{|c|c|c|c|c|c|c|}
\hline \multirow[b]{2}{*}{ Cross } & \multicolumn{3}{|c|}{ Length (mm.) } & \multicolumn{3}{|c|}{ Vertebral number } \\
\hline & & $n \bar{x}$ & S.E. & $n^{*}$ & $\bar{x}$ & S.E. \\
\hline Plaice & 94 & $8 \cdot 15$ & 0.07 & 47 & $41 \cdot 96$ & 0.05 \\
\hline Backcross & 79 & 8.88 & 0.07 & 67 & $40 \cdot 81$ & 0.12 \\
\hline Triploid & 73 & $9 \cdot 19$ & 0.07 & 65 & $40 \cdot 09$ & 0.06 \\
\hline Hybrid & 91 & $9 \cdot 60$ & 0.09 & 83 & $39 \cdot 37$ & 0.07 \\
\hline
\end{tabular}

* Not all fish were sufficiently well ossified for scoring.

crosses, and plaice $\times$ flounder triploids. The backcross group was included to test the additiveness of inheritance for meristic and morphological characters within the plaice/flounder hybrid system. For both length and vertebral number, the triploid was intermediate between the pure-bred plaice and the plaice/flounder hybrid, and the positions of the values for the backcross group were consistent with an additive inheritance for these characters. Figure 1 plots mean length and vertebral number against the

TABle 8

Ratios of length to width (l/w) in different length groups

\begin{tabular}{|c|c|c|c|c|c|c|c|c|c|c|c|c|}
\hline \multirow{2}{*}{$\begin{array}{l}\text { Length } \\
\text { group } \\
\text { range } \\
(\mathrm{mm} .)\end{array}$} & \multicolumn{3}{|c|}{ Plaice } & \multicolumn{3}{|c|}{ Backcross } & \multicolumn{3}{|c|}{ Triploid } & \multicolumn{3}{|c|}{ Hybrid } \\
\hline & n & $1 / w$ & S.E. & $n$ & $1 / w$ & S.E. & $n$ & $1 / w$ & S.E. & $n$ & $1 / w$ & S.E. \\
\hline $\begin{array}{c}<9 \cdot 0 \\
9 \cdot 0-9 \cdot 9\end{array}$ & $\begin{array}{r}66 \\
9\end{array}$ & $\begin{array}{l}3.07 \\
2.75\end{array}$ & $\begin{array}{l}0.038 \\
0.039\end{array}$ & $\begin{array}{l}39 \\
35\end{array}$ & $\begin{array}{l}3 \cdot 16 \\
2.97\end{array}$ & $\begin{array}{l}0.094 \\
0.032\end{array}$ & $\begin{array}{l}20 \\
48\end{array}$ & $\begin{array}{l}3.31 \\
2.95\end{array}$ & $\begin{array}{l}0.600 \\
0.024\end{array}$ & $\begin{array}{l}17 \\
36\end{array}$ & $\begin{array}{l}3 \cdot 17 \\
2 \cdot 74\end{array}$ & $\begin{array}{l}0.129 \\
0.032\end{array}$ \\
\hline$>9.9$ & - & - & - & 2 & $2 \cdot 73$ & 0.050 & 5 & $2 \cdot 71$ & 0.077 & 37 & $2 \cdot 49$ & 0.026 \\
\hline
\end{tabular}

proportion of plaice genetic material in the genotypes of the four groups of fish. There was no evidence against a linear regression in each case (length, $t=0.63$, d.f. $=333, \mathrm{P} \simeq 0.5$; vertebrae, $t=0.93$, d.f. $=128, \mathrm{P} \simeq 0.4$ ).

Data on the ratio of length to width are shown in table 8 for different length groups. It was necessary to examine this ratio within comparable length groups since the ratio of length to width changes rapidly during larval life as the fish approach metamorphosis. There were no consistent differences within the length groups and no evidence that triploids differed from diploids for the ratio of length to width. 

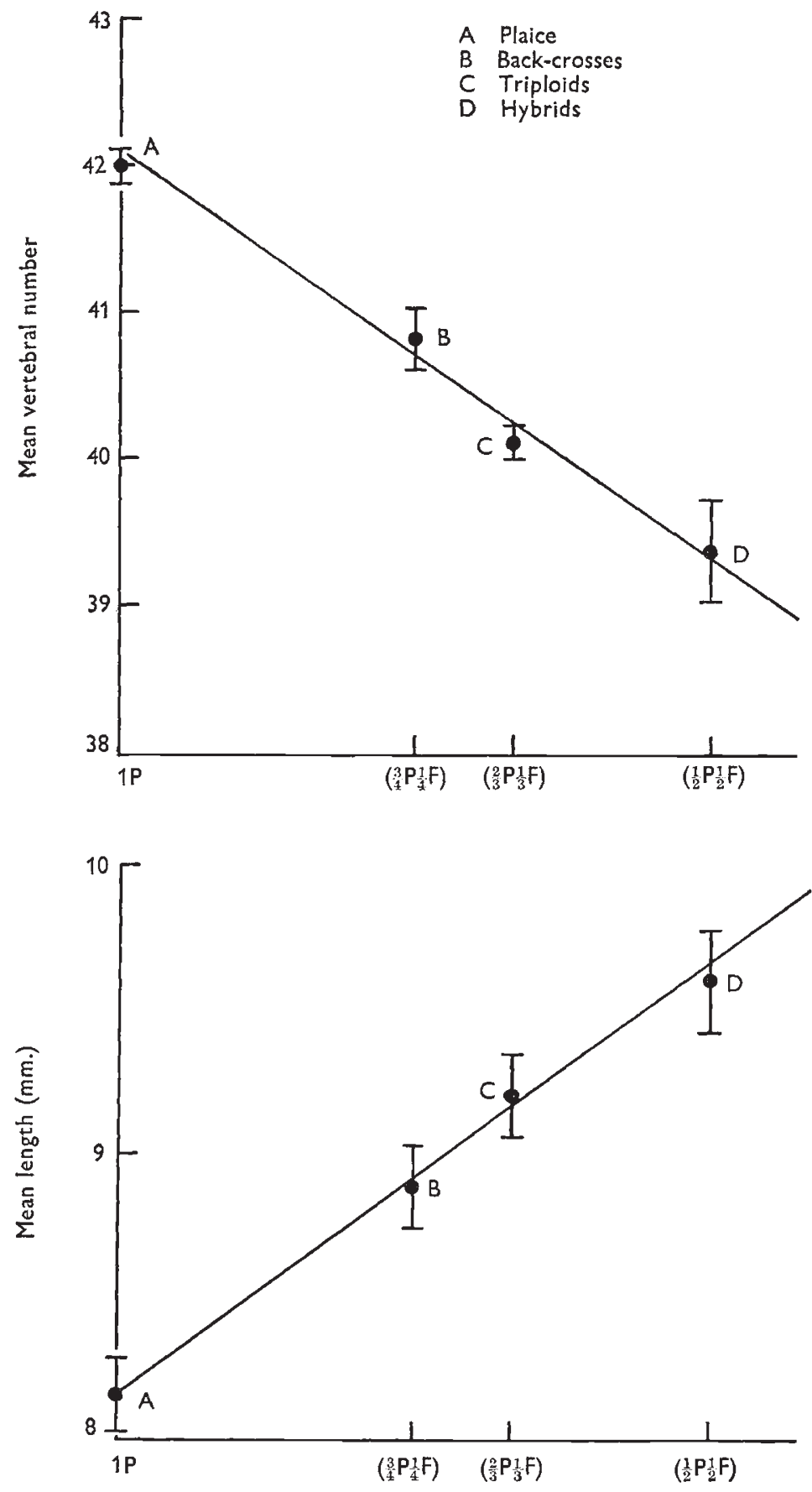

FIg. 1.-The variation in mean vertebral number and mean length at 8 weeks with the proportion of flounder genetic material $(P=$ plaice, $F=$ flounder $)$. 


\section{(e) Orientation at metamorphosis}

Plaice, and most other pleuronectids, undergo a metamorphosis with the right side uppermost. The flounder is an exception to this rule-it may be left or right side up-and this trait is also shown in plaice $\times$ flounder hybrids. In the crosses described here, the frequency of fish which metamorphosed left side up was approximately proportional to the amount of flounder genetic material present in the genome. Plaice were all right side up, whilst in the backcross, triploid and hybrid groups the frequencies of left side up fish were $2.9 \pm 2 \cdot 0$ per cent., $13.6 \pm 4.2$ per cent., and $20.9 \pm 4.4$ per cent., respectively.

\section{(f) Sex and maturation}

Sex in plaice and their hybrids with flounders can be assessed by examining the fish over an illuminated plate. Females are distinguished by a postanal extension of the coelom. There were 11 females amongst 21 triploids from a plaice $\times$ flounder cross, and in the diploid controls there were 8 females amongst 17 fish examined. The triploid condition had therefore not altered the normal sex ratio. Histological examination of gonads of 6-month-old hybrid triploids showed clear evidence of abnormal gametogenesis. The ovary of the diploid hybrid was full of developing oocytes while that of the comparable triploid contained very few oocytes (plate I). The testes of diploid and triploid hybrids were similar in histological appearance, but spermiogenesis had not begun in either. Whether or not any viable gametes are produced can only be determined when the fish have fully matured at 2 or 3 years of age, but the appearance of the ovaries at 6 months suggests that the triploids will be sterile.

\section{(g) Post-metamorphosis growth}

Four genotypes were used in the growth rate studies. These were diploid plaice, plaice $\times$ flounder hybrids and plaice $\times$ hybrid backcrosses, and triploid plaice $\times$ flounder hybrids. The backcross group was included to test the additiveness of inheritance of growth rate within the hybrid complex and because its genotype ( 25 per cent. flounder) approximated to that of the

TABLE 9

Linear regressions of the growth data illustrated in fig. 2. $\mathrm{y}=\mathrm{a}+\mathrm{bx}$, where $\mathrm{y}$ is length in $\mathrm{cm}$. and $\mathrm{x}$ the age of fish in weeks from 14 weeks after fertilisation

\begin{tabular}{lccccc}
\multicolumn{1}{c}{ Group } & $a$ & S.E. & $b$ & S.E. & $n$ \\
Plaice & 1.904 & 0.094 & 0.217 & 0.010 & 8 \\
Backcross & $2 \cdot 114$ & 0.095 & 0.327 & 0.010 & 15 \\
Triploid & 2.194 & 0.128 & 0.343 & 0.013 & 11 \\
Hybrid & 2.257 & 0.102 & 0.339 & 0.011 & 16
\end{tabular}

triploid hybrid (33 per cent. flounder). Growth curves up to about 30 weeks of age are shown in fig. 2 and suggest that the hybrids and their triploids had similar growth rates which were greater than for the plaice, with the backcross group in an intermediate position. The regression coefficients for the hybrid, backcross and triploid groups, however, were not significantly different from one another; only the plaice showed a significantly lower growth rate (table 9). The interpretation of this result is difficult because 
the eggs from which the four genotypes were derived came from females taken from different populations in the North Sea. The present trials were run in conjunction with experiments on the performance of plaice $\times$ flounder

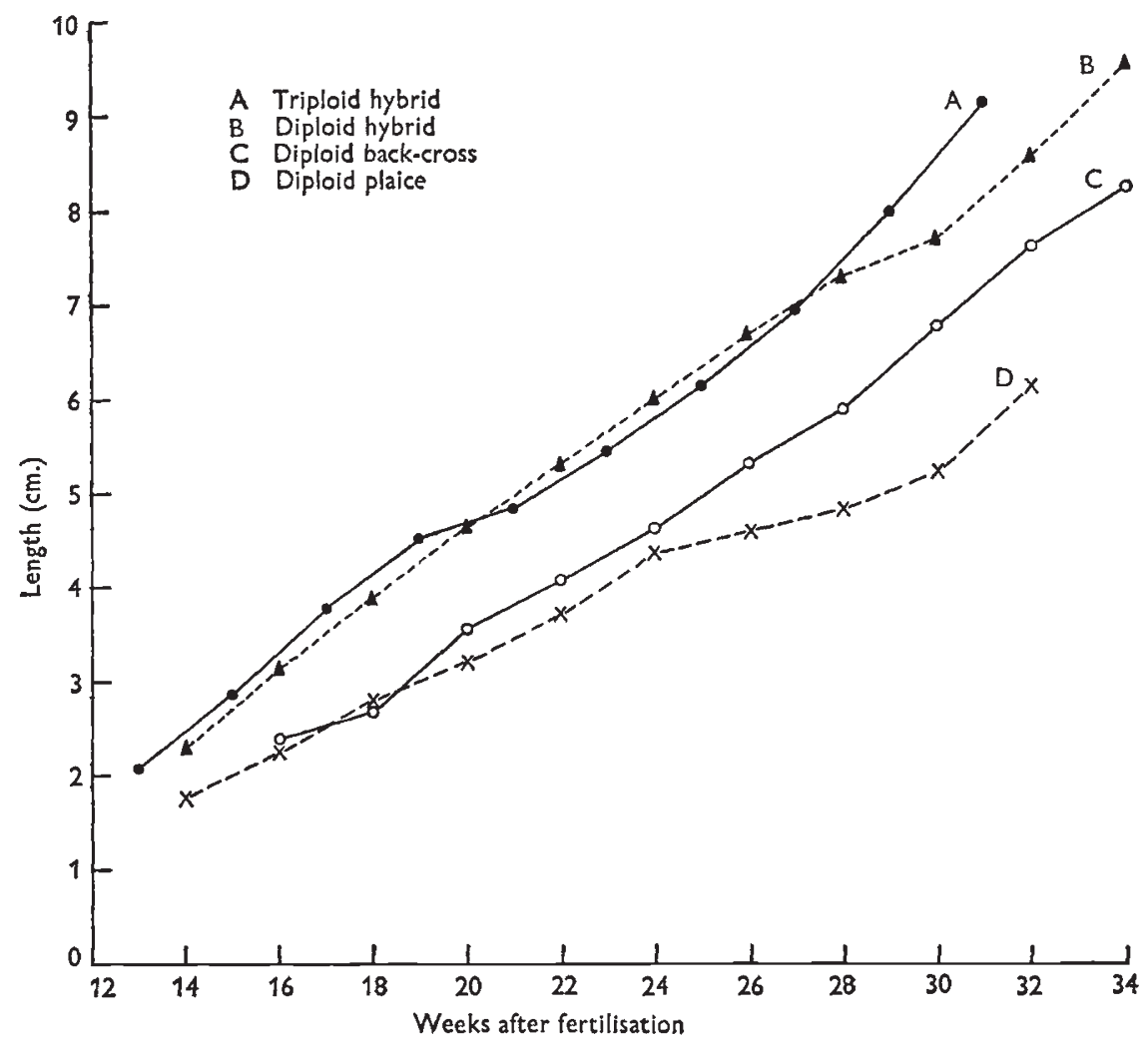

Fig. 2.-Post-metamorphosis growth.

hybrids, using females from these different North Sea populations. A more informative analysis of the growth of the plaice, backcrosses and triploids can be seen in the comparison of each of these groups with contemporaneous hybrids from the same parent, respectively (table 10). Plaice and backcross

\section{TABLE 10}

A comparison of the growth of plaice, plaice $\times$ hybrid backcrosses, and plaice $\times$ flounder triploids with their respective plaice $\times$ flounder hybrids from 14 to 34 weeks of age. Data fitted to the linear regression $\mathrm{y}=\mathrm{a}+\mathrm{bx}$, where $\mathrm{y}$ is length in $\mathrm{cm}$. and $\mathrm{x}$ is time in weeks from 14 weeks after fertilisation

Number of plaice and cross fish at

Flamborough hybrid

$$
\text { Replicate }
$$

start

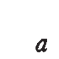

$2 \cdot 358$

$2 \cdot 465$

1.904

$2 \cdot 465$

$2 \cdot 340$

$2 \cdot 114$

$2 \cdot 498$

$2 \cdot 257$

2.194
S.E. 0.060

0.070

0.094

0.064

0.157

0.095

0.086

$0 \cdot 102$

$0 \cdot 128$
Number of fish at

S.E. finish

0.391

0.355

$0 \cdot 217$

0.375

0.392

0.327

0.338

0.339

0.343

19

$0.007 \quad 19$

$0.010 \quad 8$

$0.007 \quad 20$

$0.017 \quad 13$

$0.010 \quad 15$

$\begin{array}{ll}0.010 & 15 \\ 0.009 & 15\end{array}$

$0.011 \quad 16$

$0.013 \quad 11$ 
growth rates were significantly lower than their respective hybrid controls, the difference being much more marked for the plaice than for the backcross group. The growth rate of the triploids, however, was not significantly different from that of their control hybrids.

\section{Discussion}

Triploidy was successfully induced in plaice eggs by subjecting them to cold shocks 15 minutes after fertilisation. This parallels the observations of Swarup (1959a) on sticklebacks. No special difficulty was experienced in rearing triploids from plaice eggs, and metamorphosed triploids were as viable as diploids. This also parallels Swarup's claim that juvenile triploid sticklebacks were highly viable. In other respects, however, the present observations contrast with those on sticklebacks. Thus, amongst the coldshocked stickleback eggs there were diploid, haploid and mosaic eggs in addition to triploids. The frequencies of these varied considerably between experiments but amongst cold-shocked stickleback eggs treated for more than 1 hour there were up to 17 per cent. haploids, 18 per cent. diploids and 40 per cent. mosaics at the lens formation stage of the embryo. In the present experiments using plaice eggs. no diploids or haploids were observed and the frequency of triploids appeared to be 100 per cent. in hatching larvae. It is possible that mosaic plaice embryos would die before hatching but diploids and haploids would survive hatching, although the latter would not remain alive after hatching (Purdom, 1969). Furthermore, the survival rates in Swarup's experiments were extremely low; thus, although 55.8 per cent. of analysable embryos from cold-shocked eggs were triploid, this represented only $6 \cdot 1$ per cent. of the original fertilised eggs, and from over 4000 treated eggs only 150 juveniles were obtained, of which 24 were triploid, the rest diploid. In plaice and plaice $\times$ flounder triploids, survival from fertilisation to yolk sac absorption ( 1 week after hatching) varied from zero in cases where eggs were suspect from the start to over 60 per cent. in good quality eggs. More to the point, survivals amongst triploid eggs were usually similar to those of the diploid controls. Untreated controls were not reported in Swarup's studies and so an exact comparison of the plaice and stickleback data is impossible in this respect. Nevertheless, it seems that triploidy can be induced much more easily in plaice eggs than in stickleback eggs.

Swarup (1959a) observed that haploids, diploids and mosaics occurred not only in stickleback experiments but also in work with amphibia. $\mathrm{He}$ concluded that the haploids probably arose through androgenesis and the mosaics (haplo-diploids) through the failure of the sperm nucleus to fuse with the diploid egg nucleus; the normal diploids presumably arose through failure of the treatment to suppress the normal maturation of the egg nucleus. The assumed variable response of the eggs to temperature treatment implies that the eggs were in different stages of maturation at treatment and this may explain the difference between Swarup's observations and those in the present experiments. Plaice eggs become fully ripe after ovulation, when they take up considerable amounts of water and become hyaline. This process occurs sequentially and successive batches of eggs are ripened-and normally spawned--over a period of approximately 3 weeks. Once ovulated, the unfertilised egg has a limited life. Thus even when all ripe eggs are removed every 3 days, a proportion-sometimes as high as 50 per cent.- 
are overripe and fail to be fertilised. Thus the fertile eggs from plaice represent a very uniform sample and this may explain their uniform response to the cold treatments.

Phenotypically, the triploids induced in plaice eggs were not exceptional. There was no evidence, for example, of any morphological effect of triploidy, and in triploids from the plaice $\times$ flounder hybrid the larval pigment pattern, vertebral number and orientation at metamorphosis all reflected additive inheritance involving all three sets of chromosomes.

The sex ratio was also normal in plaice $\times$ flounder triploids. No cytological or direct genetic evidence is available on sex determination in plaice, but I-year-old diploid gynogenetic plaice showed a sex ratio of 24 females to 14 males (Purdom and Lincoln, unpublished). This suggests that in the plaice, the female is the heterogametic sex, with a WZ sex chromosome arrangement, since gynogenesis in an XX female would produce only female offspring. Sex determination in fish is commonly of the XX, $\mathrm{XY}$ type but WZ, ZZ situations are found, e.g. in Tilapia mossambica (Hickling, 1960) and Platypoesilus maculatus (Bellamy, 1922; Gordon, 1927). Assuming a WZ genotype for female plaice, the triploids would comprise equal numbers of WWZ and ZZZ plus a proportion of WZZ genotypes, depending on the frequency of crossing-over between the differential segment and the centromere. In view of the near equality of males and females amongst triploids, it seems probable that crossing-over is rare and that WWZ individuals are female and ZZZ male. This situation was slightly different in newts, where triploids were predominantly female (Fankhauser, 1940). Fankhauser and Watson (1949) assumed a WZ ZZ type of sex determination in newts and suggested that the preponderance of females could be due to equational division for the sex segment during metaphase I. This in itself, however, would give at most a sex ratio of 3 females to 1 male.

Maturation of the ovaries of triploid plaice $\times$ flounder hybrids was atypical, as expected, and very few growing oocytes were observed. It seems improbable that triploid cells with a chromosome number of $3 \mathrm{~N}=72$ could successfully complete meiosis (the probability of getting a $1 \mathrm{~N}$ or $2 \mathrm{~N}$ gamete is $\left.2 \times(0.5)^{24}\right)$. In triploid newts, Fankhauser (1940) observed a similar retardation in ovaries, although the testes of immature males seemed normal in size. Whether the rare oocytes in triploid fish will develop into viable eggs, and whether or not any viable spermatozoa can be produced can only be determined when the fish reach sexual maturity at a minimum of 2 years. The sterile triploids could be used in fish farming, where the bulk of the product is not required for reproduction. At spawning, the ovary of a plaice may be as much as 33 per cent. of the body weight (Wimpenny, 1953). The production of sterile triploids would avoid the waste of energy involved in gonad production and, because of this, should lead to better food conversion ratios and possibly an increased growth rate.

Also of interest in relation to fish farming is the possibility that triploids will grow faster than diploids, because of triploidy itself rather than its sterility effect. Swarup (1959b) concluded that triploid sticklebacks did not grow faster than diploids and that both forms reached the same final size. This was similar to the observations on triploid amphibia (reviewed by Fankhauser, 1945). In sticklebacks, as in amphibia, the increased cell size due to triploidy was compensated by a reduction in the numbers of cells per organ, and the general consensus favours an internal mechanism regulating 

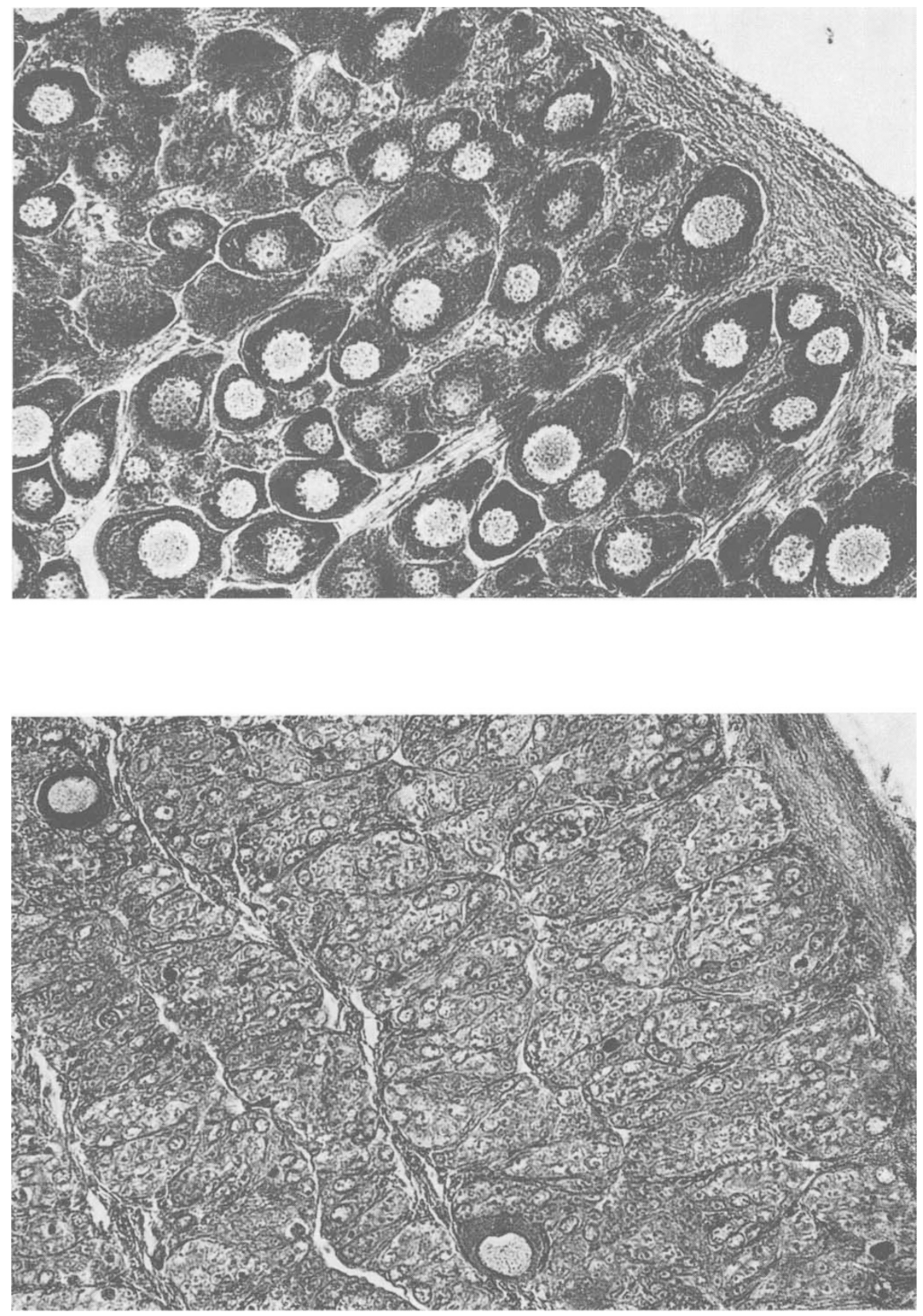

\section{Plate I}

Ovaries of 6-month-old diploid hybrids, showing many developing oocytes (above), and triploid hybrids, containing very few oocytes (below). 
growth rate. Growth in sticklebacks and in amphibia is determinate. In plaice, however, growth continues throughout the life of an individual, so that the concept of a normal size is meaningless, and size-regulatory mechanisms other than those concerned with the rate of food intake and its conversion should be absent. Under these conditions, growth rate in plaice might be proportional to the degree of ploidy, as in plants. The growth rate results with plaice $\times$ flounder triploids support this view. These triploids grew as fast as the diploid hybrids. However, the comparison of growth rates in plaice, their hybrids with the flounder, and backcrosses between plaice and hybrids indicated growth rates proportional to the amount of flounder genetic material. The triploid plaice $\times$ flounder hybrids should therefore grow less quickly than the diploid hybrids, since they contain only one-third flounder chromosome; hence the excess growth rate of the triploid over that expected could be an effect of triploidy per se. This point is being studied further, using triploid and diploid plaice.

\section{Summary}

1. The production of triploids in plaice and plaice $\times$ flounder hybrids by cold treatment of eggs 15 minutes after fertilisation was demonstrated by genetic and histological techniques.

2. Attempts to produce tetraploids failed. Cold treatment at the time of nuclear division during the first mitosis in the fertilised egg suppressed cell division but not completion of the first mitosis. The binucleate cells so produced divided twice at the second zygote mitosis and so reinstated the normal diploid condition.

3. The frequency of triploids was 100 per cent. amongst hatched larvae, and the viability of triploid embryos, larvae and juveniles appeared normal.

4. Characters which distinguish the plaice and flounder, such as vertebral number, larval pigmentation and orientation during metamorphosis, were inherited additively in the hybrid, backcross and hybrid triploid.

5. Few growing oocytes were observed in the ovaries of 6-month-old triploids. This contrasted markedly with the normal diploid pattern and suggests that the triploids will be sterile.

6. Post-metamorphosis growth rate for plaice $\times$ flounder hybrids was greater than that for plaice, and the plaice $\times$ hybrid backcross was intermediate in this respect.

7. Triploid plaice $\times$ flounder grew at the same rate as diploid hybrids, although their proportion of flounder genetic material $\left(\frac{1}{3}\right)$ was less than that of the hybrid $\left(\frac{1}{2}\right)$. It was concluded that triploidy per se may be responsible for the excess growth rate.

\section{REFERENCES}

bellamy, A. w. 1922. Sex linked inheritance in the teleost Platypoecilus maculatus Günth. Anat. Rec., 24, 419-420.

FankHauser, G. 1940. Sex-differentiation in triploid newts (Triturus viridescens). Anat. Rec., $77,227-245$.

FANKHAUSER, G. 1941. Cell size, organ and body size in triploid newts (Triturus viridescens). 7. Morph., 68, 161-177.

FANKHAUSER, G. 1945. The effects of changes in chromosome number on amphibian development. Q. Rev. Biol., 20, 20-78. 
FANKHAUSER, G., AND WATSON, R. C. 1949. The effect of pituitary implantation on diploid and triploid larvae of the newt, Triturus viridescens, with special reference to the gonads. 7. Exp. Zool., 111, 349-392.

GoRDON, M. 1927. The genetics of a viviparous top minnow, Platypoecilus; the inheritance of two kinds of melanophores. Genetics, Princeton, 12, 252-283.

Hickling, c. F. 1960. The Malacca Tilapia Hybrids. 7. Genet., 57, 1-10.

Kawamura, т. 1939. Artificial parthenogenesis in the frog. I. Chromosome numbers and their relation to cleavage histories. F. Sci. Hiroshima Univ., Ser. B1, 6, 115-218.

MAHONEY, R. 1966. Laboratory techniques in zoology, p. 268. Butterworth.

PAPE, A. 1935. Beiträge zur Naturgeschichte von Platessa pseudoflesus, ein Bastard zwischen Scholle und Flunder. Wiss. Meeresunters. Abt. Kiel., NF 22, 5, 53-88.

PURDOM, C. E. 1969. Radiation-induced gynogenesis and androgenesis in fish. Heredity, Lond., 24, 431-444.

ROMASHOV, D. D., BELYAEVA, V. N., GOLOVINSKAYA, K. A., AND PROKOF'EVA-BEL'GOVSKAYA, A. A. 1961. Radiation disease in fish. (In Russian.) Radiatsionnaya Genetika, Acad. of Sciencies USSR, Moscow, 247-266.

SUbTeLNy, s. 1958. The development of haploid and homozygous diploid frog embryos obtained from transplantation of haploid nuclei. 7. Exp. Zool., 139, 263-305.

sVÄrdson, G. 1945. Chromosome studies on Salmonidae. Meddn St. Unders.-o. FörsAust. SöttvattFisk., 23, 1-151.

SWARUP, H. 1959a. Production of triploidy in Gasterosteus aculeatus (L.). 7. Genet., 56, 129-142.

SWARUP, н. 1959b. Effect of triploidy on the body size, general organisation and cellular structure in Gasterosteus aculeatus (L.). 7. Genet., 56, 143-155.

von UBisCH, L. 1953. Uber die Zahl der Flossenstrahlen bei Pleuronectes platessa, Pl. flesus und der Bastarde und Ruckkreuzungen zwischen beiden Arten. Zool. Anz., 151, 75-86. Wimpenny, R. s. 1953. The Plaice. Arnold, London. 